\title{
In vitro Inhibition of Staphylococcus aureus Isolates by Anti-Anti-Idiotypic Antibodies to Staphylococcal Protein (SpA)
}

\author{
Angel Alberto Justiz Vaillant ${ }^{1}$, Patrick Eberechi Akpaka ${ }^{1 *}$, Monica Smikle ${ }^{2}$ and Norma McFarlane-Anderson ${ }^{3}$
}

${ }^{1}$ Departments of Paraclinical Sciences, Faculty of Medical Sciences, The University of the West Indies, St. Augustine Campus, Trinidad and Tobago

${ }^{2}$ Department of Microbiology, Faculty of Medical Sciences, The University of the West Indies, Mona Campus, Kingston, Jamaica

${ }^{3}$ Department Basic Medical Sciences, Faculty of Medical Sciences, The University of the West Indies, Mona Campus, Kingston, Jamaica

\begin{abstract}
This study investigates the ability of antibodies to SpA (a protein produced by the bacterium Staphylococcus aureus) to inhibit the growth of the bacteria. Chickens immunised with SpA produced anti -SpA antibodies in their eggs (primarily the yolk). These anti-SpA antibodies were used to feed chicks, which produce antibodies that recognise the original antigen. When these antibodies were purified from their sera and included in the growth medium of the Staphylococcus aureus, there was inhibition of the bacterial growth. This indicates that these antibodies had specifically bound to the cell surface of the bacteria and prevented growth of the bacteria, i.e. the antibodies could protect against bacterial infection. The potential of such antibody in the hyper-immune egg to act as oral therapeutic agents is discussed.
\end{abstract}

\section{Introduction}

According to Jerne's network theory, antibodies contain in their variable region a representation of the 'universe' of antigenic structures, the idiotype (Id). Therefore, an antibody can be recognized as an antigen by the immune system in normal circumstances and these interactions known as Id-anti-Id reactions can be used to manipulate the immune system [1]. Some anti-idiotypic antibodies (Ab2B) bear the internal image of an antigen $(\mathrm{Ag})$ and they have been successfully used in the induction of humoral immune responses against several antigens including bacteria and viruses [2,3]. The application of antiId as alternative to substitute conventional vaccines in their capacity to produce antibodies or $\mathrm{T}$ cell receptors with the desired specificity requires a deep understanding of the Id network interactions and how it operates in different experimental system. Anti-id vaccines have several advantages including low cost, none use of life vaccine, bypassing of the problem of antigen variation, and substituting the use of antigens with low immunogenecity e.g. polysaccharides. The purpose of this study was to use Staphylococcal protein A (SpA) as antigen to induce production of antibodies in the egg and demonstrate that animals orally fed with hyper-immune eggs developed anti-anti-Id antibodies (Ab3) with potential therapeutic effect, since they had the capacity to bind to the original antigen on the cell wall of Staphylococcus aureus and inhibited its growth.

\section{Materials and Methods}

\section{Production of anti-protein A antibodies in chickens}

Two healthy layer chickens (brown Leghorn), aged 6 months, were injected intramuscularly at multiple sites on the breast with $0.5 \mathrm{mg}$ of SpA in $0.5 \mathrm{ml}$ complete Freund's adjuvant (CFA) on day 0 , and 0.25 $\mathrm{mg}$ of the same antigen in incomplete Freund's adjuvant (IFA) on days 14, 28 and 42. The eggs were collected post-immunization. The water soluble fraction (WSF) from the egg yolk, which is rich in antibodies IgY, was separated by the method of Polson [4]. The presence of antiProtein A antibodies in the WSF was measured by enzyme-linked immunosorbent assay (ELISA).

\section{Sandwich ELISA for detection of anti-SpA antibodies}

The 96 well polystyrene microplates (U-shaped bottom) were coated with $500 \mathrm{ng}$ of SpA (Sigma-Aldrich) in coating buffer for $4 \mathrm{~h}$ at $37^{\circ} \mathrm{C}$. The microplates were washed four times with PBS-Tween-20 and blocked with $3 \%$ non-fat milk in PBS, $25 \mu \mathrm{l} /$ well, $1 \mathrm{~h}$, RT. -The microplates were washed four times again. Samples were added $50 \mu \mathrm{l}$ of the WSF of the egg yolks. After incubation for $1 \mathrm{~h}$ at RT the microplates were washed four times and $50 \mu \mathrm{l}$ of protein-A-peroxidase 1:1000 (Sigma-Aldrich) was added. The microplates were then incubated for $1 \mathrm{~h}$ at RT, washed four times. Tetramethylbenzidine (TMB) solution $(50 \mu \mathrm{l})$ was used. After a further incubation of $15 \mathrm{~min}$ in the dark, the reaction was stopped and read in a microplate reader at $450 \mathrm{~nm}$.

\section{Feeding of chicks with hyper-immune eggs}

Hyper-immune eggs with a titre of 1: 2048 were fed to eighteen (18) chicks aged zero, divided into three groups: first group was fed for 1 week, second group for 2 weeks and third group was fed for 4 weeks. Six chicks were fed non-hyper-immune egg solutions for 4 weeks. At the end of the feeding program blood samples were taken.

\section{Purification of anti-SpA antibodies in eggs and chick sera by affinity chromatography}

A commercial protein-A antibody purification system, PURE-1A (Sigma-Aldrich) was used to purify anti-SpA antibodies from the egg yolk, the egg white of hyper-immune eggs, and the sera of the chicks fed hyper-immune and non-hyper-immune eggs [5]. The instructions of the manufacturer were followed in performing this procedure.

\section{Detection of purified anti-SpA antibodies}

The presence of purified anti-SpA antibodies was investigated by the ELISA as previously described.

${ }^{*}$ Corresponding author: Patrick Eberechi Akpaka, Departments of Paraclinical Sciences, Faculty of Medical Sciences, The University of the West Indies, St. Augustine Campus, Trinidad and Tobago, Tel: +868-736-0440; Fax: +868-6633797; E-mail: peakpaka@yahoo.co.uk

Received December 21, 2011; Accepted March 05, 2012; Published March 10 2012

Citation: Justiz Vaillant AA, Akpaka PE, Smikle M, McFarlane-Anderson N (2012) In vitro Inhibition of Staphylococcus aureus Isolates by Anti-Anti-Idiotypic Antibodies to Staphylococcal Protein (SpA). J Vaccines Vaccin 3:127. doi:10.4172/21577560.1000127

Copyright: (c) 2012 Justiz Vaillant AA, et al. This is an open-access article distributed under the terms of the Creative Commons Attribution License, which permits unrestricted use, distribution, and reproduction in any medium, provided the original author and source are credited. 
Citation: Justiz Vaillant AA, Akpaka PE, Smikle M, McFarlane-Anderson N (2012) In vitro Inhibition of Staphylococcus aureus Isolates by Anti-AntiIdiotypic Antibodies to Staphylococcal Protein (SpA). J Vaccines Vaccin 3:127. doi:10.4172/2157-7560.1000127

\section{In vitro testing for the effect of purified anti-SpA antibodies on Staphylococcus aureus}

The investigation of the neutralizing capacity of purified antiSpA antibodies was carried out as follows: One $\mathrm{ml}$ of Brain Heart Infusion (BHI) broths was placed in 11 sterile test tubes. To each of these tubes was added equal volume of $10 \mu \mathrm{l}$ of purified anti-SpA antibodies in concentration of $1.28-\mu \mathrm{g} / \mu \mathrm{l}$. An inoculum of the ATCC Staphylococcus aureus strain (ATCC \#33592) was prepared to 0.5 commercially prepared McFarland scale standards (1=300 x $10^{6} / \mathrm{ml}$ bacteria concentration). Then $10 \mu \mathrm{l}$ of this inoculum was added serially from Tubes 1 to 10. None was added to Tube 11 and 12 (controls). These tubes together with preparations from the tubes were plated out on Blood agar and incubated overnight at $35^{\circ} \mathrm{C}$. Bacteria colony growth were observed in pooled sera of chicks fed with anti-SpA hyperimmune eggs up to 8 days, 15 days and 28 days period. The optical density (OD) value of the $\mathrm{Ab} 3$ was measured and plotted against the different bacterial concentration at different serial dilutions (1:10 or $0.1,1: 100$ or 0.01 and $1: 1000$ or 0.001$)$.

Statistical analysis: The chi-squared test and Fisher's exact test (Epi Info 3.5.3 software, CDC, Atlanta, GA, USA) were used as appropriate to compare the concentrations of the Staph aureus that will inhibit the growth of the bacteria for the different groups of the chicks that were the fed with anti Staph aureus A protein antibody (SpA Ab3) over the non-fed chicks (the OD value vs. the serial bacterial concentrations). The results were descriptive and were reported as comparisons of frequency distributions. A P value $<0.05$ was considered significant.

\section{Results}

\section{Production of anti-Protein A antibodies in chickens}

Anti-SpA antibodies were found in the watery soluble fraction of eggs from immunized chicken with protein A by ELISA. The titre of these antibodies was at least 10 -fold that of the eggs of the preimmune chickens 30 days post-immunization. The generation of anti-SpA antibodies was shown earlier by their purification by affinity chromatography from the egg white 13 day- and the egg yolk 20 dayspost-immunization respectively.

\section{Sandwich ELISA for detection of anti-SpA antibodies}

The sandwich ELISA was standardized by determination of reaction conditions and optimal concentrations of coating reagent, antigen, conjugate and substrate using checkerboard titration. The basis for the development of the sandwich ELISA was the determination of the presence of antibodies against protein $\mathrm{A}$ in the eggs from immunized chicken with the purified protein $\mathrm{A}$, and also to investigate whether the consumption of this hyper-immune eggs (anti-SpA) lead to the production of anti-anti-idiotypic antibodies (Ab-3) against protein $\mathrm{A}$ in response to the presence of anti-idiotypic antibodies (Ab-2) in hyper-immune eggs. Results of the assay varied according to the antiSpA concentration. It was higher in purified preparations than in the non-purified specimens e.g. serum, egg yolk, and egg white. Several photometric measurements were conducted to establish the cut-off point of the test that resulted in a mean absorbance value of at least four-fold of that of the negative controls. The sandwich ELISA showed sensitivity and specificity of $100 \%$, the use of SpA-coating micro plates and SpA-peroxidase conjugate guaranteed that only anti-SpA antibodies tested positive, since other chicken immunoglobulins does not bind to protein $\mathrm{A}$.

\section{Feeding of chicks with hyper-immune eggs}

Chicks were fed anti-SpA antibodies diluted in water and containing soya milk, which was used to decrease the antibody degradation and/or damage of their antigenic determinants by the low $\mathrm{pH}$ of the avian stomach. Chicks after the age of one day appear to be a cheaper and easy approach as a animal models for nutritional studies. They drink solutions containing hyper-immune eggs spontaneously, and thus minimizes possible deletereous effect of the stress in the experiment. Differences were observed (although not quantified) in the frequency of ingestion of the hyper-immune egg solutions, some animals preferentialy drank larger volumes than others. Its effect on the development of mucosal immune responses, where tolerance has been induced to protein antigen given orally and dosage-dependant, was not investigated.

\section{Purification of anti-SpA antibodies in eggs and chick sera by affinity chromatography}

Oral immunization of chicks with hyper-immune eggs (antiSpA) elicits "Ab-3" that binds to SpA. Each Ab-3 preparation retained strong binding capacity to the original antigen ( $\mathrm{SpA}$ ) demonstrated by ELISA. The presence of "Ab-3" in dilutions of sera up to 1:64 was investigated and tested negative. It depicted or demonstrated this by low OD. However, the purification of Ab-3 from the serum by affinity chromatography demonstrated the development of systemic immunity to orally administered anti-SpA egg yolk antibodies.

\section{In vitro testing for the effect of purified anti-SpA antibodies on Staphylococcus aureus}

Inhibiton of bacterial growth on blood agar media by the anti$\mathrm{SpA}$ antibiodies (Ab3) was clearly observed by visual inspection after overnight incubation (Picture not shown). The results obtained after comparison of the OD value vs. the serial bacterial concentrations are shown in the figures 1-3 and the Table below. Inhibition of the growth of $S$. aureus by Ab-3 purified by SpA-affinity chromatography (PURE1A) were observed in pooled sera of chicks fed with anti-SpA hyperimmune eggs up to 8, 15 and 28 days old. Inhibition were observed in very low dilutions of $S$. aureus suggesting that the Ab-3 was a mirror image of protein-A, binding to it on the cell wall of Staphylococcus

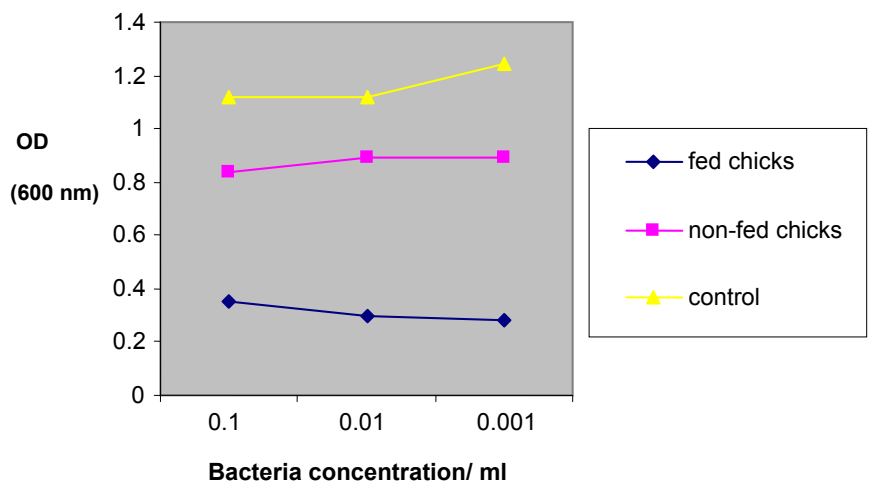

Figure 1: Inhibition of Staphylococcus growth by Ab3 in 15 daysold. Inhibition of the growth of $S$. aureus by $A b-3$ purified by $S p A$-affinity chromatography (PURE-1A) were observed in pooled sera of chicks fed with anti-SpA hyper-immune eggs up to 15 days old. Inhibition were observed in dilutions of $S$. aureus treated suggesting that the Ab-3 was a mirror image of protein-A, binding to it on the cell wall of Staphylococcus aureus and inhibiting its growth, it does not occur in non-fed chicks and controls. 


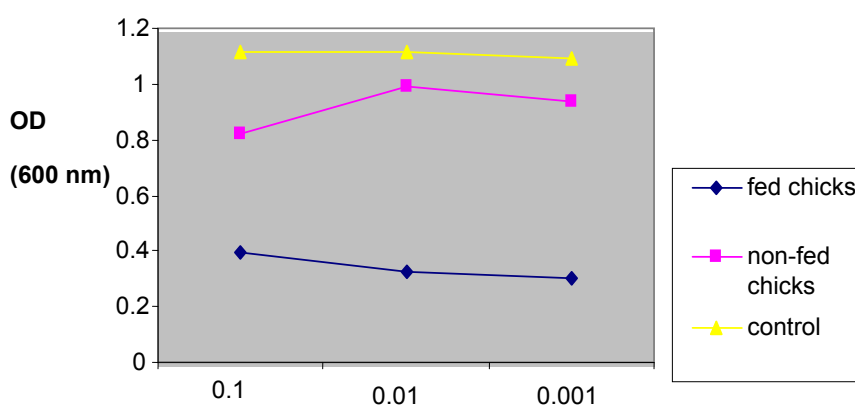

Bacteria concentration/ $\mathrm{ml}$

Figure 2: Inhibition of Staphylococcus growth by Ab3 in 4 weeks old. Inhibition of the growth of $S$. aureus by Ab-3 purified by SpA-affinity chromatography (PURE-1A) were observed in pooled sera of chicks fed with anti-SpA hyper-immune eggs up to 4 weeks old. Inhibition were observed in dilutions of $S$. aureus treated suggesting that the $A b-3$ was a mirror image of protein-A, binding to it on the cell wall of Staphylococcus aureus and inhibiting its growth, it does not occur in non-fed chicks and controls.

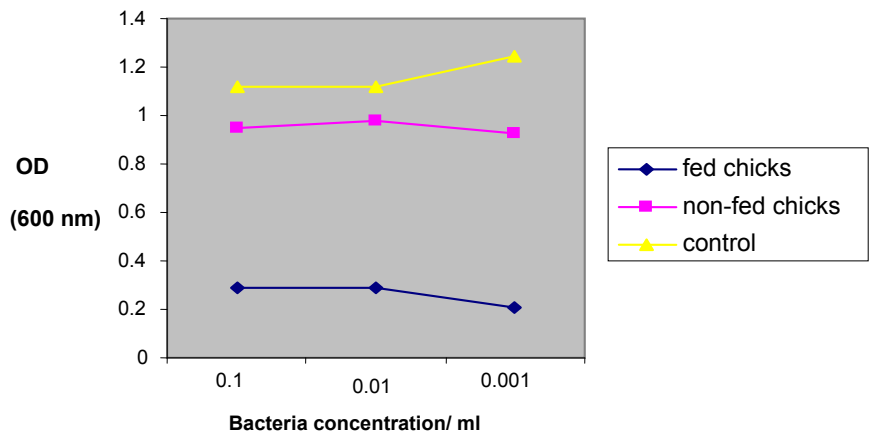

Figure 3: Inhibition of the Staphylococcus growth by Ab3. Inhibition of the growth of $S$. aureus by Ab-3 purified by SpA-affinity chromatography (PURE$1 A$ ) were observed in pooled sera of chicks fed with anti-SpA hyper-immune eggs up to 8 days old. Inhibition were observed in dilutions of $S$. aureus treated suggestin that the Ab-3 was a mirror image of protein-A, binding to it on the cell wall of Staphylococcus aureus and inhibiting its growth, it does not occur in non-fed chicks and controls. Control = bacterial suspension without Ab3. Nonfed animal $=$ fed with non-hyper immune eggs (eluate from purifications, which tested negative for the presence of Ab3 antibodies by the sandwich ELISA).

\begin{tabular}{|c|c|c|c|}
\hline Bacteria Conc $^{\mathrm{A}}$ & Fed $^{\mathrm{B}}$ & Not Fed $^{\mathbf{C}}$ & P-value \\
\hline 0.1 & 0.30 & 0.95 & $<0.001$ \\
\hline 0.01 & 0.28 & 1.0 & $<0.001$ \\
\hline 0.001 & 0.20 & 0.90 & $<0.001$ \\
\hline
\end{tabular}

$\mathrm{A}=$ Bacteria concentration in $\mathrm{ml}$ after serial dilutions; $\mathrm{B}=$ Optical density values of the bacteria growth in fed chicks; $C=$ Optical density values of the bacteria growth in chicks not fed with Ab3.

Table 1: Showing the laboratory results of bacteria growth observed in fed chicks and non fed chicks after 8 days.

aureus and inhibiting its growth._Growth of the bacteria occurred in non-fed chicks and the controls. When the bacteria concentration was $0.1 \mathrm{ml}$ the measured OD of the bacteria growth in pooled sera of chicks after 8 days was 0.39 for fed chicks and 0.83 for non fed chicks $(0.39$ vs 0.83 ; p-value $<0.001)$. This definitely means that comparisons of the inhibition of Staphylococcus aureus growth at different concentraions by $\mathrm{Ab} 3$ in 8,15 and 28 days-old chicks when fed and when not fed were statistically significant. Previous report on the inhibition of the growth of $B$. burgdorferi in an in vitro assay by specific antibodies to a surface antigen of this bacterium is has also been reported in the literature
$[6,7]$. The preparations that were streaked out on blood agar plate and incubated overnight confirmed the previous results, that there were no growth inhibition of the $S$. aureus in the dilutions that were of high concentration of the bacteria.

\section{Discussion}

The differences in the inhibition of the growth of Staphylococcus aureus in the presence of eggs from fed and non-fed animal was evident and indicates the protective capacity of Ab-3 against $\mathrm{SpA}$ and the crucial role of $\mathrm{SpA}$ in the metabolism of the cells and cell cycle (the reproductive capacity of the cell is affected when anti-SpA antibodies were present). Ab3 purified from the sera of two 8 days old chicks showed agglutination of bacteria suggesting that the isotype of these antibodies was IgM. Although this was not confirmed by any antibody typing study, IgM is well known to be involved in the primary immune response. Clearly, the formation of Ab3 is explained by the presence of immunogenic $\mathrm{Ab} 2$ and their purification from hyper-immune eggs or the sera of animals fed that provided a better understanding of these mechanisms of active immunity to egg immunoglobulins.

Two lines of evidence supporting the hypothesis of the consumption of eggs from immunized chickens (hyper immune eggs) that could serve as an oral anti-Id vaccine for the treatment of infectious diseases. The first evidence is the demonstration of BSA Id, BSA anti-Id and BSA anti-anti-Id in eggs of hens inoculated (intra-peritoneal route) with BSA, Id, and anti-Id. It has been suggested that because Id were isolated from the ova they could play a role in the regulation of the immune response and the ontogeny of the Id network of chicks [2]. The second evidence is the development of humoral and mucosal immune responses in rabbits fed daily doses of the MOPC-315 murine IgA monoclonal antibody, supporting that human exposure to xenogeneic antibodies by the oral route e.g. bovine milk immunoglobulins, may provoke the production of anti-idiotypic antibodies [8]. T lymphocytes play a central role in the generation of protective immune response against many microbial infections. A hypothesis known as relay hypothesis was earlier proposed, which explains the maintenance of immunological memory through interaction of idiotypic and antiidiotypic lymphocytes [9].

The demonstration of the capacity of hyper immune eggs to serve as oral anti-Id vaccines, generating anti-anti-Id when orally administered to chicks has not been previously reported. The use of the entire protein $\mathrm{A}$ as an antigen may likely generate Id, anti-Id and anti-anti-Id with many specificities. The formation of Ab-3 in chicks is an indirect evidence of the presence of Ab-2 in hyper-immune eggs. The protective capacity of the Ab3 to inhibit the growth of protein- $\mathrm{A}$ bearing Staphylococcus aureus in vitro proved the potential therapeutic effect of the oral hyper-immune egg and its capacity to stimulate active immune responses mediated by $\mathrm{Ab}-3$ in response to the specific egg antibodies that were orally administered to chicks. This demonstrates also that oral hyper-immune egg administration could be considered as a special type of oral anti-idiotypic vaccines. The presence of specific anti-SpA in the egg yolk makes the egg a potential immunotherapeutic agent against Staphylococcus aureus [10].

Production of antibodies in chickens is advantageous since large amount of antibodies can be isolated from the hyper-immune eggs at low cost and since chickens are able to produce antibodies in response to any Ag including those with low immunogenecity. IgY does not fix complement, and does not bind to cellular Fc receptors. The egg 
Citation: Justiz Vaillant AA, Akpaka PE, Smikle M, McFarlane-Anderson N (2012) In vitro Inhibition of Staphylococcus aureus Isolates by Anti-AntiIdiotypic Antibodies to Staphylococcal Protein (SpA). J Vaccines Vaccin 3:127. doi:10.4172/2157-7560.1000127

yolk antibody technology is an alternative method to the blood taking techniques and is less stressful to animals. Hens can be kept under nearly natural condition. Avian antibodies have been shown to be in use in some applications even more effective than mammalian antibodies. The use of hyper immune eggs as oral anti-idiotypic vaccine in the way we describe here could be advantageous for the large amount of antibodies produced, low cost, the reduction of antigenic variation, toxicity and danger implicit in the use of live vaccines.

\section{Conclusion}

In vitro Inhibition of Staphylococcus aureus isolates by anti-antiidiotypic antibodies to staphylococcal protein (SpA) was successfully demonstrtated in this study. This indicates that these antibodies had specifically bound to the cell surface of the bacteria and prevented growth of the bacteria; and this highly suggests that the antibodies could protect against bacterial infection.

\section{References}

1. Jerne NK (1974) Towards a network theory of the immune system. Ann Immunol 125C: 373-389.

2. Ainsworth AJ, Brown JE (1991) Detection of in ovo derived idiotypic antibodies. I. A model for maternal-neonatal idiotype network studies. J Immunol 147: 910 914
3. Zhang $\mathrm{H}$, Ainsworth AJ (1994) Investigation of the poultry idiotypic network using Pasteurella multocida. Vet Immunol Immunopathol 41: 73-88.

4. Polson A (1990) Isolation of IgY from the yolks of eggs by a chloroform polyethylene glycol procedure. Immunol Invest 19: 253-258.

5. Spaccapelo R, Janse CJ, Caterbi S, Franke-Fayard B, Bonilla JA, et al. (2010) Plasmepsin 4-Deficient Plasmodium berghei are Virulence Attenuated and Induce Protective Immunity against Experimental Malaria. Am J Pathol 176 205-217.

6. Khalafalla RE, Daugschies A (2010) In vivo evaluation of anticoccidial effect of antibody fragments expressed in pea (Pasum sativum) on Eimeria tenella sporozoites. Parasitol Res 107: 983-986.

7. Sadziene A, Thompson PA, Barbour AG (1993) In vitro inhibition of Borrelia burgdorferi growth by antibodies. J Infect Dis 167: 165-172.

8. Collins AM, Roberton DM, Hosking CS, Flannery GR (1991) Oral immunization with xenogeneic antibodies stimulates the production of systemic and mucosal anti-idiotypic antibodies. Immunology 73: 388-393.

9. Lal G, Shaila MS, Nayak R (2006) Recombinant idiotypic TCRbeta chain immunization in mice generates antigen specific T cell response. Mol Immuno 43:1549-1556.

10. Wang LH, Li XY, Jin LJ, You JS, Zhou Y, et al. (2011) Characterization of chicken egg yolk immunoglobulins (IgYs) specific for the most prevalent capsular serotypes of mastitis-causing Staphylococcus aureus. Vet Microbio 149: 415-421. 